\title{
Co-Electrodeposition of Metallic Precursors for the Fabrication of CZTSe Thin Films Solar Cells on Flexible Mo Foil
}

\author{
M. I. Khalil, ${ }^{a}$ R. Bernasconi, ${ }^{a}, *$ L. Pedrazzetti, ${ }^{a}$ A. Lucotti, ${ }^{b}$ A. Le Donne, ${ }^{c}$ S. Binetti, ${ }^{c}$ \\ and L. Magagnin ${ }^{\mathrm{a}, * *, \mathrm{z}}$ \\ ${ }^{a}$ Department of Chemistry, Materials and Chemical Engineering Giulio Natta, Politecnico di Milano, 20131 Milano, \\ Italy \\ ${ }^{b}$ Department of Chemistry, Materials and Chemical Engineering Giulio Natta, Politecnico di Milano, 20133 Milano, \\ Italy \\ ${ }^{c}$ Department of Material Science and Solar Energy Research Centre (MIB-SOLAR), University of Milano-Bicocca, \\ 20125 Milano, Italy
}

\begin{abstract}
Earth abundant $\mathrm{Cu}_{2} \mathrm{ZnSnSe}_{4}$ (CZTSe) thin films solar cells were fabricated on flexible molybdenum (Mo) foil substrate through an electrochemical approach. After co-electroplating from single electrolyte, $\mathrm{Cu}-\mathrm{Zn}$-Sn $(\mathrm{CZT})$ precursor was selenized in quartz tube furnace at $550^{\circ} \mathrm{C}$ for 15 minutes in Ar atmosphere with the presence of elemental selenium in order to form CZTSe compound. Before selenization, CZT precursor was soft-annealed at $310^{\circ} \mathrm{C}$ for 150 minutes in Ar atmosphere in order to improve intermixing of the elements and to reduce roughness. The formation of Kesterite CZTSe on selenized film was confirmed by X-ray diffraction (XRD) and Raman spectroscopy. SEM imaging and EDS line profile on the cross-section of CZTSe layer showed the well-formed CZTSe along depth of the film also. Opto-electrical characteristics of the film by photoluminescence spectroscopy confirmed the suitability of the absorber layer to make solar cell. A flexible solar cell with Al/Al-ZnO/i-ZnO/CdS/CZTSe/Mo-foil configuration, which showed $0.1 \%$ power conversion efficiency at first attempt, has been fabricated, in which buffer layer CdS has been deposited through chemical bath deposition and transparent conducting oxides (i- $\mathrm{ZnO}, \mathrm{Al}-\mathrm{ZnO}$ ) have been deposited by DC pulsed sputtering. (C) The Author(s) 2017. Published by ECS. This is an open access article distributed under the terms of the Creative Commons Attribution Non-Commercial No Derivatives 4.0 License (CC BY-NC-ND, http://creativecommons.org/licenses/by-nc-nd/4.0/), which permits non-commercial reuse, distribution, and reproduction in any medium, provided the original work is not changed in any way and is properly cited. For permission for commercial reuse, please email: oa@electrochem.org. [DOI: 10.1149/2.1001706jes] All rights reserved.

(cc) BY-NC-ND
\end{abstract}

Manuscript submitted February 13, 2017; revised manuscript received March 20, 2017. Published March 31, 2017.

Thin films solar cells based on earth abundant Kesterite $\mathrm{Cu}_{2} \mathrm{ZnSn}(\mathrm{S}, \mathrm{Se})_{4}$ absorber layers have drawn significant attention within the research community over the last few years as future low cost photovoltaic devices in order to meet global energy demand in tera-watt scale. These materials are direct bandgap p-type semiconductors for which the bandgap ranges from $1.0 \mathrm{eV}$ for $\mathrm{Cu}_{2} \mathrm{ZnSnSe}_{4}$ (CZTSe) to $1.5 \mathrm{eV}$ for $\mathrm{Cu}_{2} \mathrm{ZnSnS}_{4}$ (CZTS) and at the same time they have very high optical absorption coefficients of over $10^{4} \mathrm{~cm}^{-1}$ which make them potential alternative as absorber layer for existing commercialized thin films solar cells $\mathrm{Cu}_{2} \mathrm{InGaSe}_{4}$ (CIGS) and CdTe. ${ }^{1}$ As CIGS and CdTe contain earth scarce, costly and toxic materials, so they need to be replaced. Different vacuum and non-vacuum techniques have already been employed to fabricate high quality crystalline Kesterite compounds. Up to now, highest $12.6 \%$ power conversion efficiency of sulfo-selenide $\mathrm{Cu}_{2} \mathrm{ZnSn}(\mathrm{S}, \mathrm{Se})_{4}$ thin film solar cell was achieved using hydrazine based solution process. ${ }^{2}$ Whereas highest power conversion efficiencies of pure sulfide CZTS (obtained from evaporation) and pure selenide CZTSe (obtained from sputtering) thin film solar cells are $9.2 \%$ and $11.6 \%$ respectively reported. ${ }^{3,4}$ Those highest power conversion efficiencies were achieved when conventional molybdenum (Mo) coated soda lime glass was used as a back contact substrate. On the other hand, till now highest power conversion efficiencies of CZTS and CZTSe thin film solar cells on flexible substrate were reported $4.2 \%$ and $6.1 \% .^{5,6}$ In order to reduce production costs and deployment of thin film PV-based technologies in mass scale, Kesterite-based thin film solar cells technologies should be manufacturable at high throughput with low cost and they should exhibit good power conversion efficiency. Fabrication of Kesterites on flexible substrate has high potential to decrease production cost due to roll-to-roll manufacturing on flexible substrate, which enables use of compact size deposition equipment with high throughput. ${ }^{7}$ Molybdenum, stainless steel, aluminum, titanium, etc. are potential candidates as flexible metal foils substrates because they are cheap,

\footnotetext{
*Electrochemical Society Student Member.

**Electrochemical Society Member.

${ }^{\mathrm{z} E-m a i l: ~ l u c a . m a g a g n i n @ p o l i m i . i t ~}$
}

durable, lightweight and sustainable at high temperature sulfurization or selenization process. Moreover, there is no need of metallic back contact layer when metallic substrate is used. Mo particularly gets more priority as a back contact because it does not require any barrier layer in solar cell. In addition to this, Mo has good thermal stability, high conductivity and compatible linear thermal expansion, CTE $\left(5.2 \times 10^{-6} \mathrm{~K}^{-1}\right) .{ }^{8}$ Electrodeposition is a promising technique for the fabrication of Kesterite, since it is a low cost and non-vacuum method that allows low temperature uniform growth over large substrate area with good control over the metallic composition and morphology. More importantly, if compared to different vacuum based techniques and wet chemical methods, the materials utilization rate in electrodeposition is better than $90 \%$ partly due to the selectivity and partly because there is extensive know-how on the re-use and recycle of electrodeposition electrolytes. ${ }^{9}$ Electrodeposition has already been used to fabricate Kesterite based thin film solar cells. With electrodeposition- annealing process, till now $8 \%$ and $8.2 \%$ efficient CZTS and CZTSe thin film solar cells have been fabricated on conventional Mo coated soda lime glass. ${ }^{10,11}$ There are limited reports on the fabrication of Kesterite based thin film solar cells on flexible substrates. In 2014, Lopez-Marino et al. fabricated CZTSe thin film solar cells on flexible stainless steel foil with $3.5 \%$ power conversion efficiency through sputtering-annealing route. ${ }^{12}$ In 2016, the same group showed good efficiency improvement of CZTSe thin film solar cells on flexible stainless steel. They achieved $6.1 \%$ efficiency of CZTSe thin film solar cells with optimizing different back contact characteristics. In their work, Mo: $\mathrm{Na}$ ( $\mathrm{Na}$ doped Mo) layer and $\mathrm{Cr}$ diffusion barrier layer were used in between stainless steel and Mo layer in order to get $\mathrm{Na}$ as dopant for increasing the conductivity during illumination and prevent the migration of $\mathrm{Fe}$ atoms during selenization respectively. Moreover, their highest efficiency was obtained when Mo:Na layer had been doped by Ge. ${ }^{6}$ Though CZTS has been fabricated on flexible Mo foil before, ${ }^{8,13,14,16}$ reports on fabrication of CZTSe on flexible Mo foil has not been demonstrated yet in any publication according to current literature review. In addition to this, there has been no report on fabrication of CZTSe thin film solar cells through electrodeposition-annealing process on flexible substrates. In the present work, we have fabricated CZTSe thin films 
solar cells on flexible Mo foil through electrodeposition-annealing route for the first time. Here at first $\mathrm{Cu}-\mathrm{Zn}$-Sn $(\mathrm{CZT})$ precursor has been co-electrodeposited from a single electrolyte. Later, CZT precursor has been chalcogenided with the presence of selenium powder at $550^{\circ} \mathrm{C}$ for 15 minutes. Resulting CZTSe has been characterized and subsequently used as active material for the manufacturing of flexible solar cells.

\section{Experimental}

$\mathrm{Cu}-\mathrm{Zn}-\mathrm{Sn}$ (CZT) precursor was prepared galvanostically by coelectrodeposition approach from single electrolyte which has been described in our previous article. ${ }^{14}$ Flexible Mo foil $(200 \mu \mathrm{m}$ thick, from Goodfellow) substrate with an exposed area of $1.6 \times 2.0 \mathrm{~cm}^{2}$ was used as a working electrode while titanium mesh was used as inert counter electrode. Deionized water was used during making of the electrolyte from the water purification system (Millipore). Electrodeposition has been carried out using Amel Model-549 Potentiostat with $4.5 \mathrm{~mA} / \mathrm{cm}^{2}$ current density for 8 minutes. Rotating working electrode was used during co-electrodeposition of CZT in order to get perfect homogeneous distribution of elements, less void or pitting in the films and smooth surface. After preparing the CZT precursor through electrodeposition, sample was soft annealed at $310^{\circ} \mathrm{C}$ for 150 minutes in a quartz tube furnace with the presence of inert $\mathrm{Ar}$ atmosphere. Later soft annealed CZT precursor was selenized at $550^{\circ} \mathrm{C}$ for 15 minutes in a quartz tube furnace with the presence of $25 \mathrm{mg}$ elemental selenium powder (Sigma Aldrich; reagent grade, 100 mesh particle size). During selenization, $20^{\circ} \mathrm{C} /$ minute ramping rate (heating rate) was used based on our previous studies and in order to make inert atmosphere like soft annealing step, a very small flow of Ar has been maintained throughout the process. ${ }^{14}$ The p-n junction has been formed by depositing n-type semiconductor $\mathrm{CdS}(\approx 70 \mathrm{~nm})$ from chemical bath deposition on top of p-type semiconductor CZTS. ${ }^{15}$ Later, a 80 $\mathrm{nm}$ intrinsic $\mathrm{i}-\mathrm{ZnO}$ buffer layer in order to prevent any shunts, was deposited by RF sputtering. After that transparent conducting oxide (TCO) layer consisting of $350 \mathrm{~nm}$ Al-doped $\mathrm{ZnO}$ (AZO) was grown by DC pulsed $(2 \mathrm{kHz})$ sputtering. At last, solar cells were completed by evaporating an $\mathrm{Al}$ grid contact on top of $\mathrm{AZO}$. By this way flexible $\mathrm{Al} / \mathrm{Al}-\mathrm{ZnO} / \mathrm{i}-\mathrm{ZnO} / \mathrm{CdS} / \mathrm{CZTSe} / \mathrm{Mo}$-foil device has been prepared, following standard production protocols for devices with sputtered adsorbers, except for the electrodeposited layer. The crystallographic phases present in the as-deposited co-electrodeposited CZT precursor, soft-annealed CZT precursor and selenized CZTSe films were analyzed by X-ray diffraction (XRD), using a Philips X-pert MPD with $\mathrm{CuK} \alpha=1.5406 \AA$ radiation. The cross-sectional morphology, compositional profile at interface and chemical compositions of the samples were analyzed by Scanning Electron Microscopy (Model Zeiss EVO 50) equipped with energy dispersive X-ray spectroscopy (EDS) (Oxford instrument, Model 7060). To acquire the compositional line profile across the interface at CZTSe/Mo, the sample was mounted in resin and mechanically polished to mirror-like finish. The morphology of the cross-section was observed after breaking the sample in liquid nitrogen. Raman spectroscopy measurements were carried out in air at room temperature with a micro-Raman spectrometer (Horiba Jobin-Yvon Labram HR800) in backscattering configuration. The instrument is equipped with an optical microscope and an Ar-ion laser (Stabilite 2017, Spectra Physics). The $514.5 \mathrm{~nm}$ excitation line has been used for the characterization of the samples. Here outcoming power of laser was $100 \mathrm{~mW}$, which then decreased to $1 \mathrm{~mW}$ onto substrate after passing through the filtering systems to avoid any sample local heating. Photoluminescence (PL) measurements were performed with a spectral resolution of $6.6 \mathrm{~nm}$ using a standard lock-in technique in conjunction with a single grating monochromator and a short wavelength enhanced InGaAs detector with maximum responsivity at $1540 \mathrm{~nm}$. A quantum well laser $\left(\lambda_{\mathrm{exc}}=805 \mathrm{~nm}\right)$ with a power density of $15.5 \mathrm{~W} \mathrm{~cm}^{-2}$ was used as excitation source. A cooling system consisting of rotary pump, turbomolecular pump and He closed circuit cryostat was used to perform PL spectra at $15 \mathrm{~K}$. Solar cell J-V measurements were taken under Air Mass 1.5 conditions (simulating

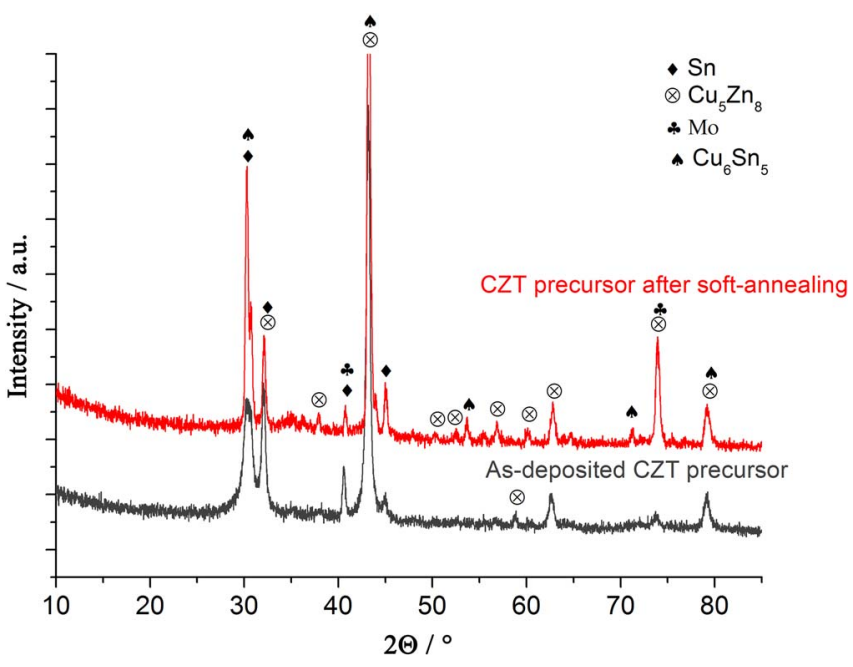

Figure 1. XRD pattern of as-deposited CZT precursor and soft-annealed CZT precursor.

terrestrial applications) with a Abet Lot-Oriel Solar simulator with constant incident power density of 1 Sun $\left(100 \mathrm{~mW} / \mathrm{cm}^{2}\right)$ and with Keithley 2440 source meter.

\section{Results and Discussion}

The precursor, before and after soft-annealing, and the selenized film were analyzed using XRD to determine their microstructure. Fig. 1 illustrates the XRD patterns of as-deposited $\mathrm{Cu}-\mathrm{Zn}$-Sn (CZT) precursor and soft-annealed CZT precursor after annealing at $310^{\circ} \mathrm{C}$ for 150 minutes. Long duration of soft-annealing has been chosen in order to improve the intermixing of the metallic elements and to reduce the roughness of the precursor according to previous study. ${ }^{10}$ It is evident from the Fig. 1 that as-deposited CZT precursor consists of pure metallic Sn (JCPDS card 86-2265) and cubic $\mathrm{Cu}_{5} \mathrm{Zn}_{8}$ alloy (JCPDS card 25-1228) phases which have already been reported in our earlier articles. ${ }^{14,16}$ Besides this, like in our previous work, here also $\mathrm{Cu}$-poor, Zn-rich CZT precursor has been used to fabricate CZTSe, as those compositions are ideal for the fabrication of Kesterite based thin films. ${ }^{14,16,17}$ The atomic composition of as-deposited CZT precursor measured by EDS was $\mathrm{Cu}: 44.1 \%, \mathrm{Zn}: 28.9 \%$ and $\mathrm{Sn}$ : $26.9 \%(\mathrm{Cu} / \mathrm{Zn}+\mathrm{Sn}=0.79, \mathrm{Zn} / \mathrm{Sn}=1.07)$. It was observed that after soft-annealing, comparatively intensity of pure metallic Sn peak was reduced and intensity of cubic $\mathrm{Cu}_{5} \mathrm{Zn}_{8}$ peak was increased as well as some more $\mathrm{Cu}_{5} \mathrm{Zn}_{8}$ peak emerged which was not visible in XRD pattern of as deposited CZT precursor. In addition to this, some new peaks of hexagonal $\eta-\mathrm{Cu}_{6} \mathrm{Sn}_{5}$ (JCPDS card 47-1575) alloy also appeared in soft-annealed CZT precursor which means intermixing has been done properly. Fig. 2 shows the XRD pattern of selenized film which mostly exhibited the peaks related to the Kesterite structure of CZTSe (JCPDS 00-052-0868), without having any significant reflections for any other compounds except those associated with bottom Mo layer and $\mathrm{MoSe}_{2} \cdot{ }^{18,19}$ Here, dominant peak of polycrystalline CTZSe

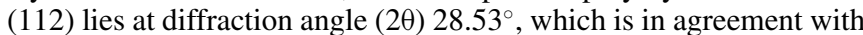
literature. ${ }^{18-21} \mathrm{MoSe}_{2}$ (JCPDS 29-0914) which usually forms at the interface between CZTSe and bottom Mo layer was observed at diffraction angles $31.2^{\circ}$ and $55.9^{\circ}$. The broadening of $\mathrm{MoSe}_{2}$ peaks indicate its poor crystallinity. Though the effect of $\mathrm{MoSe}_{2}$ on the power conversion efficiency of thin film solar cells is a debatable issue, recently it has been reported that the formation of $\mathrm{MoSe}_{2}$ interfacial layer at the CZTSe/Mo interface enhances the quasi-ohmic electrical contact when it forms with appreciable thickness. ${ }^{22}$ Conversely, a thick $\mathrm{MoSe}_{2}$ layer at the CZTSe/Mo interface can increase the overall series resistance of the device like in case of CIGS/Mo. ${ }^{23}$ In order to support the XRD results, Raman spectroscopy has been performed on selenized 


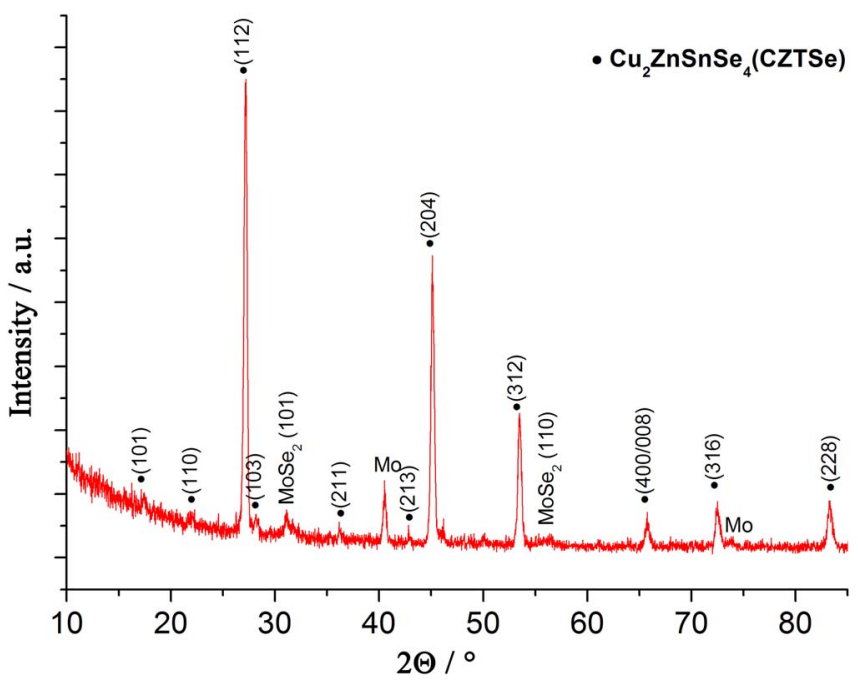

Figure 2. XRD pattern of selenized CZTSe films.

CZTSe film, as XRD diffraction peaks of CZTSe coincidences with binary $\mathrm{ZnSe}$ and ternary intermediate $\mathrm{Cu}_{2} \mathrm{SnSe}_{3}$. This is due to the fact that they are analogous with zincblende related crystal structure. Raman scattering results for the top of selenized CZTSe is shown in Fig. 3. During Raman measurement, $514.5 \mathrm{~nm}$ excitation wavelength of laser source was used, so penetration depth of laser source could be in the range of $150 \mathrm{~nm}$ according to the studies of Fernandes et al. ${ }^{24}$ Raman spectra reveal three Raman peaks corresponding to CZTSe at $172 \mathrm{~cm}^{-1}, 195 \mathrm{~cm}^{-1}$ and $234 \mathrm{~cm}^{-1}$ Raman shift along with most intense peak at $195 \mathrm{~cm}^{-1}$ which are in agreement with the previous studies. ${ }^{18-21}$ No peak corresponding to any secondary phases of $\mathrm{Cu}_{2} \mathrm{Se}, \mathrm{Cu}_{2} \mathrm{SnSe}_{3}$ or $\mathrm{SnSe}$ was observed, suggesting the formation of pure crystalline CZTSe phase. The atomic chemical composition of selenized film by scanning electron microscope equipped with EDS is also in agreement with the pure crystalline CZTSe phase. The average atomic composition of CZTSe found by EDS was: $\mathrm{Cu}: 25.10 \%, \mathrm{Zn}$ : $13.82 \%$, Sn: $14.31 \%$ and Se: $46.77 \%$ which are very near to the stoichiometric compositional ratio of CZTSe. Photoluminescence (PL) spectroscopy has been performed on selenized CZTSe film in order to study the quality of the semiconductor for solar cells application. The PL spectra often show asymmetric broad peak at photon energy ranging from $0.85 \mathrm{eV}$ to $1.02 \mathrm{eV}$ depending upon the growth parameters of films, coexistence of secondary phases with CZTSe, coexistence

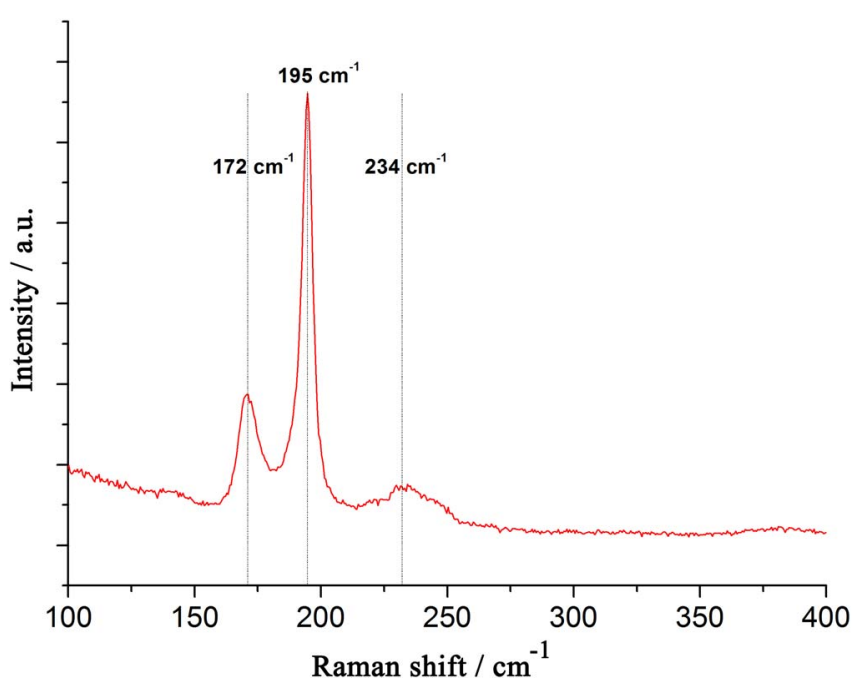

Figure 3. Raman spectrum of selenized CZTSe film.

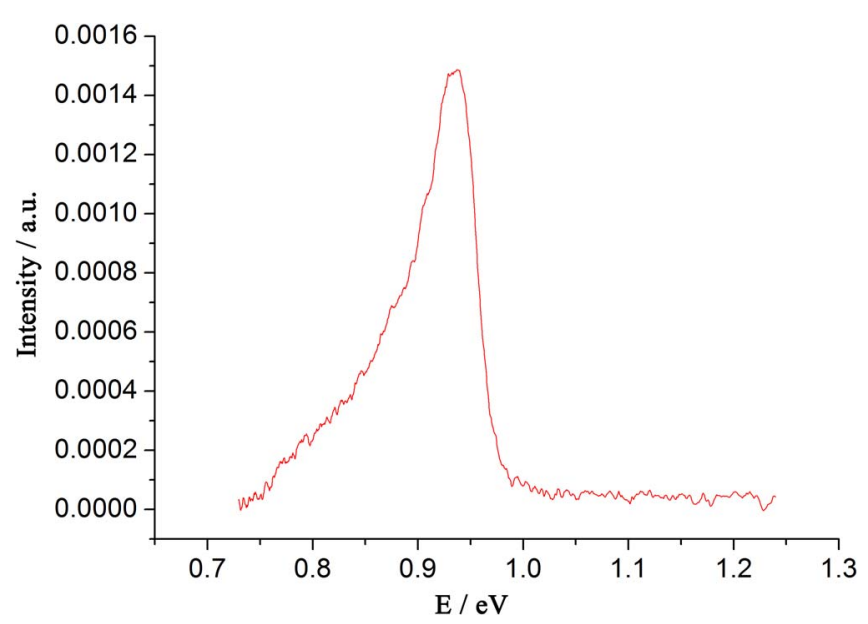

Figure 4. Photoluminescence spectrum (PL) of selenized CZTSe collected at $15 \mathrm{~K}$ (For comparison, see PL spectrum for sputtered CZTSe in Reference 31).

of different polymorphs of CZTSe, concentrations gradients of constituent elements, etc. ${ }^{25}$ Low temperature PL spectra of such films demonstrate a single broad and asymmetrical band attributed to band tail related and quasi-donor-acceptor pairs recombination. ${ }^{26}$ Fig. 4 shows the low temperature (15K) photoluminescence (PL) spectra of selenized CZTSe film deposited on Mo foil at $550^{\circ} \mathrm{C}$ for 15 minutes. Here PL spectra shows an asymmetric broad peak at $0.94 \mathrm{eV}$ which is in agreement with other studies where it has been attributed to valence band tail related transitions. ${ }^{27-29}$ This also indicates spatial potential fluctuations in the material that are caused by high concentration of randomly distributed charged defects. ${ }^{30}$ However PL spectra of high performing pure selenide CZTSe devices show a peak close to $1 \mathrm{eV}^{31}$ In order to determine the phase uniformity of crystalline CZTSe along the film thickness, selenized CZTSe sample was further characterized by SEM-EDS line profile along the cross-section of the film. It is evident from Fig. 5, that signal intensities of $\mathrm{Cu}, \mathrm{Zn}, \mathrm{Sn}$ and Se have not shown any significant variations along the depth of the film, though much noise has been observed in all line profile of constituent elements. Point to be noted, here line intensity of $\mathrm{Cu}$ and $\mathrm{Zn}$ has been multiplied by two times in order to compare all line profiles. Noise was originated from surface roughness which happened due to the surface preparation of the cross-section of the sample. In addition, line profile of $\mathrm{Zn}$ signal shows an upward trend near to the

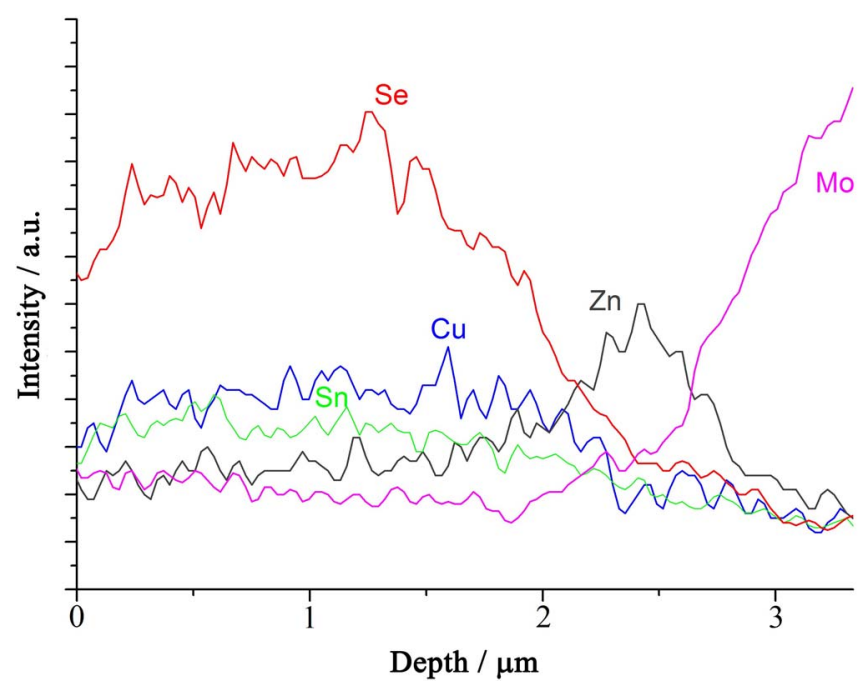

Figure 5. SEM-EDS line profile along the cross section of the selenized CZTSe film. 


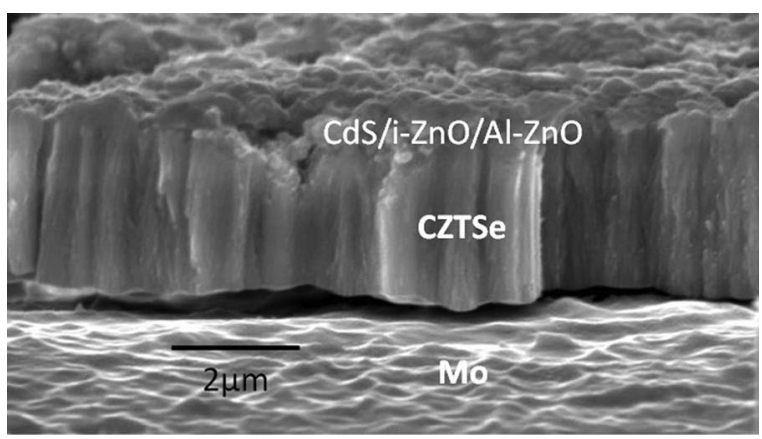

Figure 6. SEM cross-sectional image of CZTSe thin film device.

interface of CZTSe/MoSe 2 . This can be related to the formation of $\mathrm{ZnSe}$ at the interface which can negatively impact the performance of the solar cell depending upon location, size and fabrication method. ${ }^{32}$ ZnSe phase cannot be confirmed by XRD as it coincides with diffraction peaks of other phases or by Raman spectroscopy as $\mathrm{ZnSe}$ forms below the penetration depth of laser sources. This insulating n-type ZnSe semiconductor has high bandgap which blocks current at the interface hence increasing series resistance of the solar cell devices according to the studies of Redinger et al. ${ }^{28}$ On the other hand, Mo signal from substrate did not show any sharp upward trend in SEMEDS line profile at the interface of CZTSe/Mo. Formation of $\mathrm{MoSe}_{2}$ has already been confirmed by XRD analysis. Fig. 6 shows the SEM cross-sectional image of CZTSe thin film solar cells with the configuration of $\mathrm{Al} / \mathrm{Al}-\mathrm{ZnO} / \mathrm{i}-\mathrm{ZnO} / \mathrm{CdS} / \mathrm{CZTSe} / \mathrm{Mo}$-foil. It is evident from the figure that well-textured crystalline CZTSe with large grain size has been formed after selenization. It has been reported by many studies, that Kesterites possess bimodal grain distribution where smaller grains are located near the interface of Mo and larger grains at the top of the kesterite surface. ${ }^{16,33}$ However, here we observed large grain size of CZTSe along the cross-section without having any particular grain size distribution, void, pores, pinholes etc. Our growth parameters during the fabrication of CZTSe might be the reason behind it. From the J-V characteristics of the solar cells, with the typical trend of a device governed by series resistance, ${ }^{34}$ we have found that power conversion efficiency (PCE) of CZTSe thin film solar cells under AM 1.5 illumination was $0.1 \%$ with $\mathrm{Jsc}=3.9 \mathrm{~mA} / \mathrm{cm}^{2}$ and $\mathrm{Voc}=119$ $\mathrm{mV}$ in our first attempt. Investigation and optimization of different layers of solar cells, likely with more attention for those produced through wet processes, are needed in order to understand the reason behind such low efficiency and series resistance behavior. Point to be noted, that still highest efficiency of Kesterite based thin films solar cells after optimizing different layers with inclusion of buffer layer and alkali material on flexible substrate is less than half with respect to highest efficiency on conventional Mo coated soda lime glass.

\section{Conclusions}

CZTSe thin films have been fabricated on flexible Mo foil through electrodeposition-annealing route for the first time. A CZTSe thin films solar cell with $\mathrm{Al} / \mathrm{Al}-\mathrm{ZnO} / \mathrm{i}-\mathrm{ZnO} / \mathrm{CdS} / \mathrm{CZTSe} / \mathrm{Mo}$-foil configuration has been prepared which showed $0.1 \%$ power conversion efficiency in our first measurement of the cells. Different characterization techniques like XRD, Raman, photoluminescence, crosssectional analysis by SEM etc. have ensured well-formed crystalline CZTSe after selenization of CZT precursor. Low lifetime and reduced efficiency of PV devices can be attributed to the band tail related and quasi-donor-acceptor pairs recombination. Moreover, segregation of $\mathrm{Zn}$ related to $\mathrm{ZnSe}$ phase formation was observed near to the interface of CZTSe/Mo, which has a detrimental effect on the conversion efficiency of the solar cells. At the same time, formation of $\mathrm{MoSe}_{2}$ was also observed at the interface of CZTSe/Mo. Further characterizations are needed in order to identify the effects $\mathrm{MoSe}_{2}$ on the conversion efficiency of the solar cells with respect to its thickness.

\section{Acknowledgments}

This work was partially funded by University of Milano-Bicocca with the grant "Fondo di ateneo quota competitiva" project n. 2016ATESP-0582.

\section{References}

1. K. Ito and T. Nakazawa, Electrical and optical properties of stannite-type quaternary semiconductor thin films, Jpn. J. Appl. Phys., 27, 2094 (1988).

2. W. Wang, M. T. Winkler, O. Gunawan, T. Gokmen, T. K. Todorov, Y. Zhu, and D. B. Mitzi, Device characteristics of CZTSSe thin-film solar cells with $12.6 \%$ efficiency, Adv. Energy Mater., 4, 1301465 (2014).

3. T. Kato, H. Hiroi, N. Sakai, S. Muraoka, and H. Sugimoto, Characterization of front and back interfaces of $\mathrm{Cu}_{2} \mathrm{ZnSnS}_{4}$ thin-film solar cells, 27th EU PVSEC, 2012.

4. Y. S. Lee and T. Gershon, , O. Gunawan, , T. K. Todorov, , T. Gokmen and ,Y. Virgus, , and $\mathrm{S}$. Guha, $\mathrm{Cu}_{2} \mathrm{ZnSnSe}_{4}$ Thin-film Solar cells by thermal co-evaporation with $11.6 \%$ efficiency and improved minority carrier diffusion length, Adv. Energy Mater. 5, 1401372 (2015)

5. P. Bras, J. Sterner, and C. Platzer-Björkman, Influence of hydrogen sulfide annealing on copper-zinc-tin-sulfide solar cells sputtered from a quaternary compound target Thin Solid Films, 582, 233 (2015).

6. S. Lopez-Marino, Y. Sanchez, M. Espındola-Rodriguez, X. Alcobe, H. Xie, M. Neuschitzer, I. Becerril, S. Giraldo, M. Dimitrievska, M. Placidi, L. Fourdrinier, V. Izquierdo-Roca, A. Perez-Rodrıguezad, and E. Saucedoa, Alkali doping strategies for flexible and light-weight $\mathrm{Cu}_{2} \mathrm{ZnSnSe}_{4}$ solar cells, J. Mater. Chem. A, 4, 1895 (2016).

7. P. Reinhard, A. Chirila, P. Blosch, F. Pianezzi, S. Nishiwaki, S. Buecheler, and A. N. Tiwari, Review of progress toward $20 \%$ efficiency flexible CIGS solar cells and manufacturing issues of solar modules, IEEE J. Photovoltaics, 3, 572 (2013).

8. Y. Zhang, Q. Ye, J. Liu, H. Chen, X. He, C. Liao, J. Han, H. Wang, J. Meib, and W. M. Laub, Earth-abundant and low-cost CZTS solar cell on flexible molybdenum foil, $R S C A d v, \mathbf{4}, 17703$ (2014)

9. H. Deligianni, S. Ahmed, and L. T. Romankiw, The next frontier: Electrodeposition for solar cell fabrication, Interface, 20, 47 (2011)

10. F. Jiang, S. Ikeda, T. Harada, and M. Matsumura, Pure sulfide $\mathrm{Cu}_{2} \mathrm{ZnSnS}_{4}$ thin film solar cells fabricated by preheating an electrodeposited metallic stack, Adv. Energy Mater, 4, 1301381 (2014).

11. L. Vauche, L. Risch, Y. Sanchez, M. Dimitrievska, M. Pasquinelli, T. G. Monsabert, P. -P. Grand, S. Jaime-Ferrer, and E. Saucedo, $8.2 \%$ pure selenide kesterite thin-film solar cells from large-area electrodeposited precursors, Prog. Photovolt: Res. Appl., 24, 38 (2016)

12. S. Lopez-Marino, M. Neuschitzer, Y. Sánchez, A. Fairbrother, M. Espindola-Rodriguez, J. López-García, M. Placidi, L. Calvo-Barrio, A. Pérez-Rodríguez, and E. Saucedo, Earth-abundant absorber based solar cells onto low weight stainless steel substrate, Sol. Energy Mater. Sol. Cells, 130, 347 (2014).

13. R. L. Oliveri, G. Ferrara, P. Liveri, S. Piazza, C. Sunseri, and R. Inguanta, Investigation of annealing conditions on electrochemically deposited CZTS film on flexible Molybdenum foil, J. Electrochem. Soc., 163, 532 (2016)

14. M. I. Khalil, R. Bernasconi, and L. Magagnin, CZTS layers for solar cells by an electrodeposition-annealing route, Electrochim. Acta, 145, 154 (2014).

15. A. Le Donne, S. Marchionna, P. Garattini, R. A. Mereu, M. Acciarri, and S. Binetti, Effects of CdS buffer layers on photoluminescence properties of $\mathrm{Cu}_{2} \mathrm{ZnSnS}_{4}$ solar cells, Int. J. Photoenergy, 2015, 583058 (2015).

16. M. I. Khalil, R. Bernasconi, S. Ieffa, A. Lucotti, S. Binetti, A. Le Donne, and L. Magagnin, Effect of co-electrodeposited $\mathrm{Cu}-\mathrm{Zn}$-Sn precursor compositions on the final sulfurized CZTS thin films for solar cell, ECS Transactions, 64, 33 (2015).

17. M. I. Khalil, O. Atici, A. Lucotti, S. Binetti, A. Le Donne, and L. Magagnin, CZTS absorber layer for thin film solar cells from electrodeposited metallic stacked precursors (Zn/Cu-Sn), Appl. Surf. Sci., 379, 91 (2016).

18. J. Li, T. Ma, M. Wei, W. Liu, G. Jiang, and C. Zhu, The $\mathrm{Cu}_{2} \mathrm{ZnSnSe}_{4}$ thin films solar cells synthesized by electrodeposition route, Appl. Surf. Sci., 258, 6261 (2012).

19. L. Guo, Y. Zhu, O. Gunawan, T. Gokmen, V. R. Deline, S. Ahmed, L. T. Romankiw, and $\mathrm{H}$. Deligianni, Electrodeposited $\mathrm{Cu}_{2} \mathrm{ZnSnSe}_{4}$ thin film solar cell with $7 \%$ power conversion efficiency, Prog. Photovolt: Res. Appl., 22, 58 (2014).

20. L. Vauche, J. Dubois, A. Laparre, F. Mollica, R. Bodeux, S. Delbos, C. M. Ruiz, M. Pasquinelli, F. Bahi, and T. G. Monsabert, $\mathrm{Cu}_{2} \mathrm{ZnSnSe}_{4}$ thin film solar cells above $5 \%$ conversion efficiency from electrodeposited $\mathrm{Cu} \mathrm{Sn} \mathrm{Zn}$ precursors, Phys. Status Solidi A, 211, 2082 (2014)

21. J. Iljina, O. Volobujeva, T. Raadik, N. Revathi, J. Raudoja, M. Loorits, R. Traksmaa, and E. Mellikov, Selenisation of sequentially electrodeposited $\mathrm{Cu}-\mathrm{Zn}$ and $\mathrm{Sn}$ precursor layers, Thin Solid Films, 535, 14 (2013).

22. S. E. Habas, H. A. S. Platt, M. F. A. M. vanHest, and D. S. Ginley, Low-cost inorganic solar cells: from ink to printed device, Chemical Reviews, 110, 6571 (2010).

23. K. J. Hsiao, J. D. Liu, H. H. Hsieh, and T. S. Jianga, Electrical impact of $\mathrm{MoSe}_{2}$ on CIGS thin-film solar cells, Phys. Chem. Chem. Phys., 15, 18174 (2013)

24. P. A. Fernandes, P. M. P. Salome, and A. F. Da Cunha, Study of polycrystalline $\mathrm{Cu}_{2} \mathrm{ZnSnS}_{4}$ films by Raman scattering, J. Alloys Compouds, 509, 7600 (2011).

25. R. Djemour, A. Redinger, M. Mousel, L. Gutay, and S. Siebentritt, Multiple phase of $\mathrm{Cu}_{2} \mathrm{ZnSnSe}_{4}$ detected by room temperature photoluminescence, J. Appl. Phys., 116, 073509 (2014) 
26. M. V. Yakushev, J. Márquez-Prieto, I. Forbes, P. R. Edwards, V. D. Zhivulko, A. V. Mudryi, J. Krustok, and R. W. Martin, Radiative recombination in $\mathrm{Cu}_{2} \mathrm{ZnSnSe}_{4}$ thin films with $\mathrm{Cu}$ deficiency and $\mathrm{Zn}$ excess, J. Phys. D: Appl. Phys., 48, 475109 (2015).

27. M. Grossberg, J. Krustok, K. Timmo, and M. Altosaar, Radiative recombination in $\mathrm{Cu}_{2} \mathrm{ZnSnSe}_{4}$ monograins studied by photoluminescence spectroscopy, Thin Solid Films, 517, 2489 (2009).

28. A. Redinger, K. Hones, X. Fontane, V. Izquierdo-Roca, E. Saucedo, N. Valle, A. Perez-Rodriguez, and S. Siebentritt, Detection of a $\mathrm{ZnSe}$ secondary phase in coevaporated $\mathrm{Cu}_{2} \mathrm{ZnSnSe}_{4}$ thin films, Appl. Phys. Lett., 98, 101907 (2011).

29. J. Marquez-Prieto, M. V. Yakushev, I. Forbes, J. Krustok, P. R. Edwards, V. D. Zhivulko, O. M. Borodavchenko, A. V. Mudryi, M. Dimitrievska, V. Izquerdo-Roca, N. M. Pearsall, and R. W. Martin, Impact of the selenisation temperature on the structural and optical properties of CZTSe absorbers, Sol. Energy Mater. Sol. Cells, 152, 42 (2016).
30. E. Kask, M. Grossberg, R. Josepson, P. Salu, K. Timmo, and J. Krustok, Defect studies in $\mathrm{Cu}_{2} \mathrm{ZnSnSe}_{4}$ and $\mathrm{Cu}_{2} \mathrm{ZnSn}\left(\mathrm{Se}_{0.75} \mathrm{~S}_{0.25}\right)_{4}$ by admittance and photoluminescence spectroscopy, Mater. Sci. Semicond. Process., 16, 992 (2013).

31. S. Oueslati, G. Brammertz, M. Buffière, H. ElAnzeery, O. Touayar, C. Köble, J. Bekaert, M. Meuris, and J. Poortmans, Physical and electrical characterization of high-performance $\mathrm{Cu}_{2} \mathrm{ZnSnSe}_{4}$ based thin film solar cells, Thin Solid Films, 582, 224 (2015).

32. G. Y. Kim, D. H. Son, T. T. T. Nguyen, S. Yoon, M. Kwon, C. W. Jeon, D. H. Kim, J. K. Kang, and W. Jo, Enhancement of photo-conversion efficiency in $\mathrm{Cu}_{2} \mathrm{ZnSn}(\mathrm{S}, \mathrm{Se})_{4}$ thin-film solar cells by control of $\mathrm{ZnS}$ precursor-layer thickness, Prog. Photovolt: Res. Appl., 24, 292 (2016).

33. S. Ahmed, K. B. Reuter, O. Gunawan, L. Gao, L. T. Romankiw, and H. Deligianni, A high efficiency electrodeposited $\mathrm{Cu}_{2} \mathrm{ZnSnS}_{4}$ solar Cell, Adv. Energy Mater, 2, 53 (2012).

34. K. Mertens, Photovoltaics: Fundamentals, Technology and Practice, John Wiley \& Sons (2013) 